\title{
An Innovation for Retarded Healing Process of a Chronic Ulcer by Aloe Vera Gel Treatment
}

\author{
Majid Avijgan ${ }^{1 *}$, Mahtab Avijgan ${ }^{2}$, Atousa Hakamifard ${ }^{3}$ and Niloufar Razavi ${ }^{4}$ \\ 'Department of Iranian Traditional Medicine, Department of Infectious Diseases, Isfahan University of Medical \\ Sciences, Alzahrah Hospital, Isfahan, Iran; avijgan@yahoo.com \\ 2University of New Castel, NSW, Australia \\ ${ }^{3}$ Nosocomial Infection Research Center, Isfahan University of Medical Sciences, Isfahan, Iran \\ ${ }^{4}$ Department of Infectious Diseases, Isfahan University of Medical Sciences, Isfahan, Iran
}

\begin{abstract}
In some cases of chronic ulcers of soft tissue cannot be treated by conventional treatment methods. In recent years some alternative methods have been proposed for treatment of such ulcers on the basis of Traditional Iranian (Persian) Medicine. This reports a case of chronic ulcer treatment by using Aloe vera gel. The ulcer was caused by car accident and in spite of using conventional treatment the injury remained for 60 days without appropriate response to therapy. Because of stopping in healing process by Aloe vera gel, this was discontinued and potassium permanganate has been used. After drying the ulcer using the alternative method of Aloe vera gel and potassium permanganate together has been applied and then the Aloe vera gel was used until the complete healing of ulcer. The delayed healing process of Aloe vera gel raise the question whether it is solely effective in complete healing of chronic ulcer or requires adjuvant therapies. Although Aloe vera is effective in healing process of chronic ulcer but sometimes it may be ineffective so that we are obliged to use potassium permanganate as an adjuvant drug which is presented by this case report.
\end{abstract}

Keywords: Aloe Vera Gel, Chronic Ulcer, Herbal Medicine, Medicine, Traditional Iranian (Persian)

\section{Introduction}

Twenty four percent of Americans have a pressing ulcer of at least stage two at death time ${ }^{1}$. Bedsore have been a great concern for elder people and caused to limit their movement. The onset of bedsores has more importance in society with increasing the number of elderly people ${ }^{2}$. The damaged skin, will share a considerable consequences for people and society. On the base of reports the costs of care and treatment of bedsores can reach up to 8.5 million dollars ${ }^{3}$. The topical treatment of ulcers is one of the important aspects of care of ulcer and even though it is in the next level after surgical procedure and systematic looking after, but there is no strong evidence to prove which one of these patterns have more effectiveness to treatment ${ }^{4}$.

Topical care of pressing ulcers, includes: cleaning ulcer, debridement and dressing ${ }^{5}$. In addition to current methods of treatment, several alternative methods for treating chronic ulcers have been presented. Pressing ulcer with collagen induces to production of the desirable granulation and vascularization on ulcer and

\footnotetext{
*Author for correspondence
}

Email: avijgan@yahoo.com 
will have considerable antibacterial effect ${ }^{6}$. The basic and clinical studies have indicated compatibility of collagen compress and its effect on promoting up the process of re-epitelization ${ }^{7}$.

Herbal treatment has been confirmed, like use of natural oily essence as antiseptic for treatment methods ${ }^{8}$. Among different herbal medicine, Aloe vera (SabrZard) is a well-known herb in Traditional Iranian Medicine (TIM), which previous studies have indicated its curative impression on chronic ulcers treatment ${ }^{9}$. This herb or plant is aborigine in the Middle East area and have been described in TIM, s textbooks in detail. Mohammad Hossein Aghili, one of the famous Iranian physicians at about 300 years ago, has described its effective treatment in his famous book as Makhzan-al-adviyeh. Based on this book, Aloe vera has three kinds: Arabic, Indian and Persian. In other TIM, s textbook like Al-Havi written by Rhazes (865 - 925) and Canon in medicine Written by Avicenna (980-1037) are mentioned to Aloe vera. Due to remarkable repetitions, Aloe vera (Sabrzard) in TIM textbook, it is a native herb in Iran. One of the treatment effectiveness of Aloe vera is chronic ulcer treatment. This reports the treatment of patient with foot chronic ulcer (resulting from accident) no respond to systematic treatment and even Aloe vera gel, but was treated by alternate use of Aloe vera gel and permanganate potassium.

\section{Introducing the Patient}

The patient was a 65-year-old household woman, who two months before referring to clinic due to a car accident involved to three ulcers on the medial aspect of her left lower limb. The woman was under treating by debridement operation, antiseptic solution and antibiotics but they did not work effectively. When she was referred to clinic, three ulcers were observed in pretibial area and behind her left foot with approximate measurements $20 \times 30,30 \times 30$ and $30 \times 40 \mathrm{~mm}$. (re 1)

The ulcers were extended into two layers of epidermis and dermis where granulation tissue, necrotic margin and somehow supportive serous secretion had lead to debilitating effect on patient.

In clinical examination of patient there was no fever and lymph adenopathy and laboratory tests were within normal range as: $\mathrm{CBC}$ and Differentiation, Erythrocyte Sedimentation Rate (ESR), Urine Analysis (UA), creatinine (Cr), Blood Urea Nitrogen (BUN), potassium (K), sodium(Na), Fasting Blood Sugar (FBS). The Chest $\mathrm{X}$ ray showed not any abnormality, PPD test was less than $5 \mathrm{~mm}$ and $\mathrm{X}$ ray of tibia was normal.

Skin graft was suggested for treatment in orthopedic consultation, but patient rejected.

Based on previous studies and having experience of the effectiveness of Aloe vera gel dressing on chronic ulcer $^{9-11}$, the patient was treated by using Aloe vera gel in the last stage.

\section{Preparation and Application of Gel}

Aloe vera is available in Esfahan medicinal herbs magazine of Attari (A magazine where sells the traditional herbs). This study has used the fresh typical of Aloe vera herb. After the lower leaves of Aloe vera was

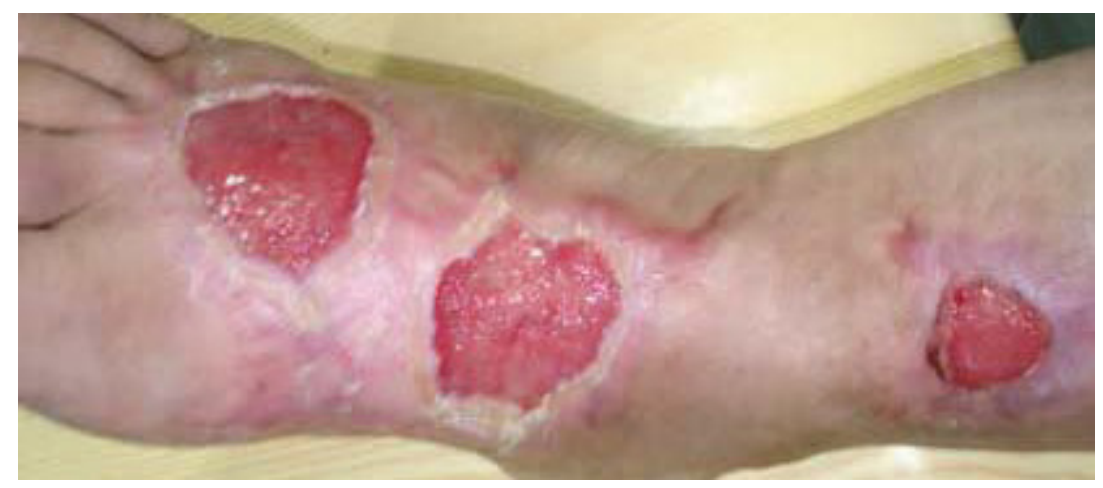

Fig. 1. The first presentation of ulcer when she referred to us. 


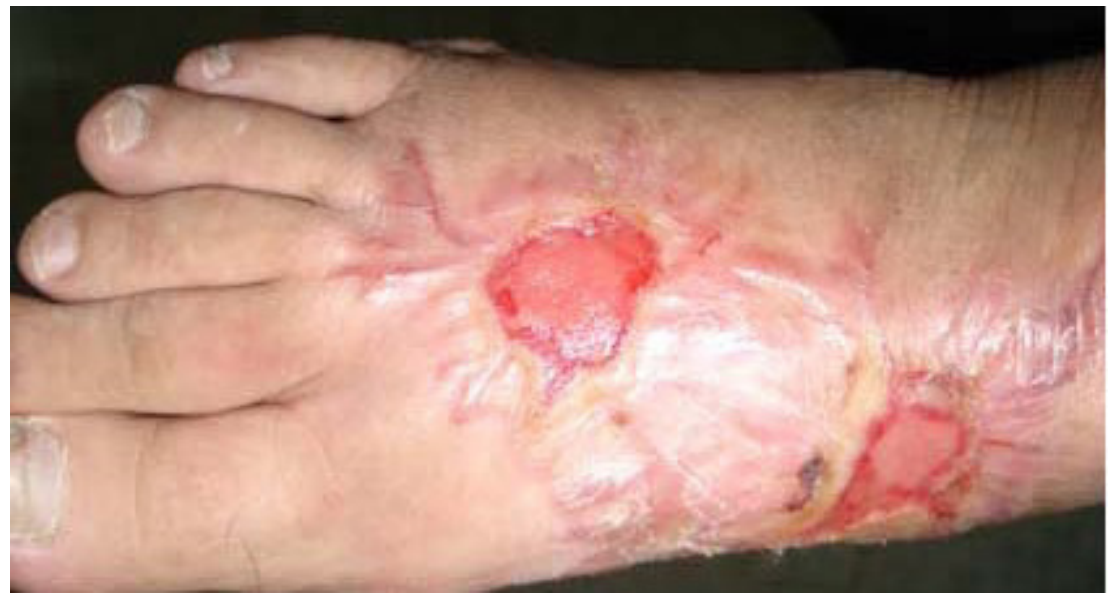

Fig. 2. The presentation of ulcer after 3 weeks treatment by AVG.

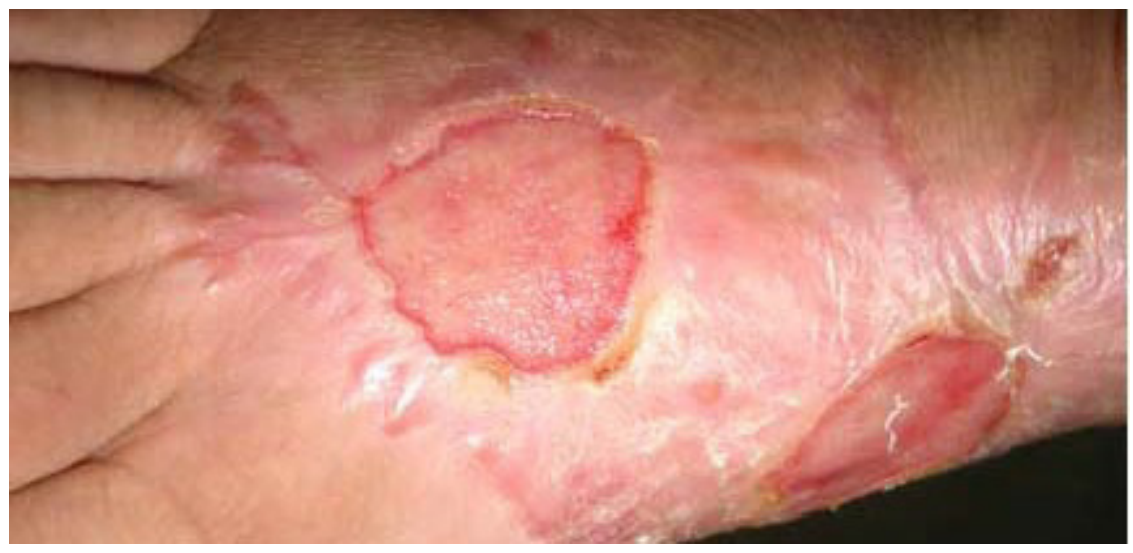

Fig. 3. The presentation of ulcer after 7 weeks treatment by AVG.

separated, the internal gel was collected and mixed with lubricant gel (ECG lubricant gel) 5:1 as a preservative. (Lubricant gel made by Iran, treatment instruments factory, Salem brand). The solution contains $85 \mathrm{~g}$ of water-soluble lubricant. The patient was treated by Aloe vera gel dressing two times a day for two weeks. In third week redness of ulcer, secretion and pain was reduced (Figure 2).

Therefore using Aloe vera gel was continued and suggested to follow up for one month. In next visit (next month) the size of the ulcer was bigger than last visit and accompanied by secretion in the form of a wet ulcer (Figure 3).

Since 2000 and by experience of treatment of such ulcers by Aloe vera gel, it was the first time to face with the phenomena of stopping the healing process by Aloe vera gel. So it was discontinued and treatment with potassium permanganate $\left(\mathrm{KMnO}_{4}\right)$ was used. The potassium permanganate is called Dada goly (Rose Drug) in TIM. In TIM this is a drying drug for wet ulcers (Al-Havi, Cannan in medicine).

\section{Application of Potassium Per- manganate}

Potassium permanganate solution may cause the ulcer as an adverse effect. Prescribing the potassium permanganate needs to some precaution to avoid from such complication ${ }^{12}$. Usually it is recommended to patients to use potassium permanganate solution, with a shower and the most important recommendation is to 


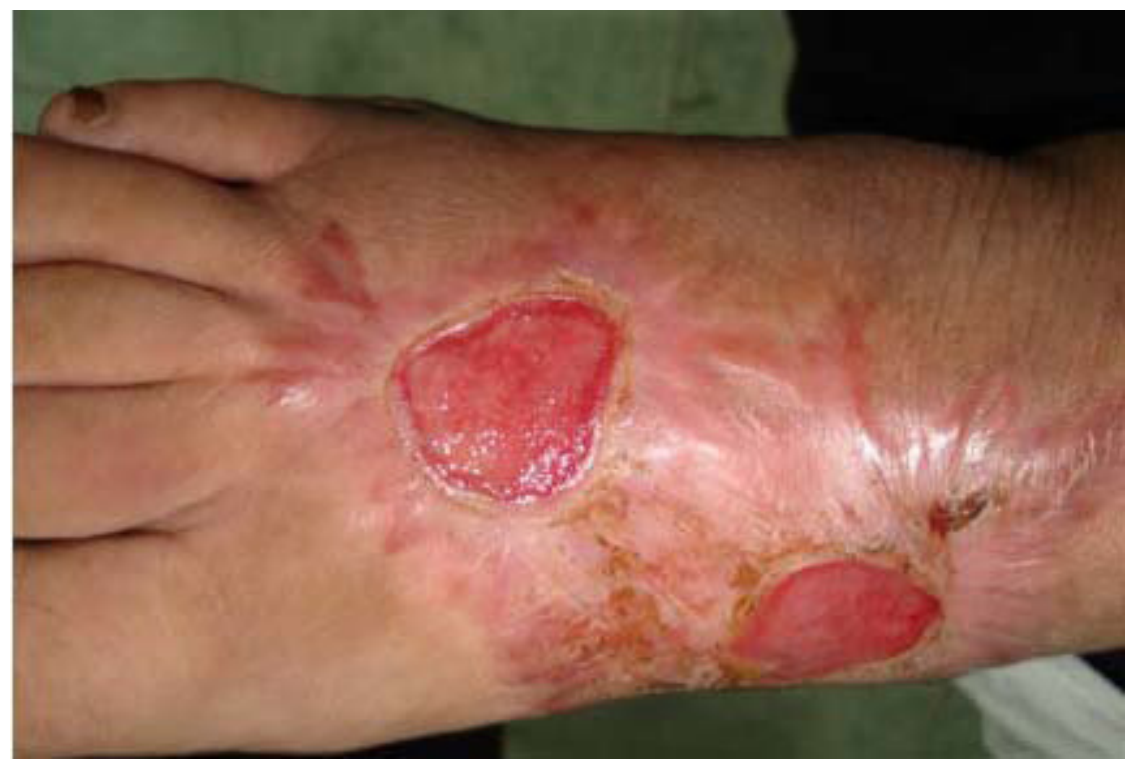

Fig. 4. The presentation of ulcer after 2 weeks treatment by potassium permanganate alone.

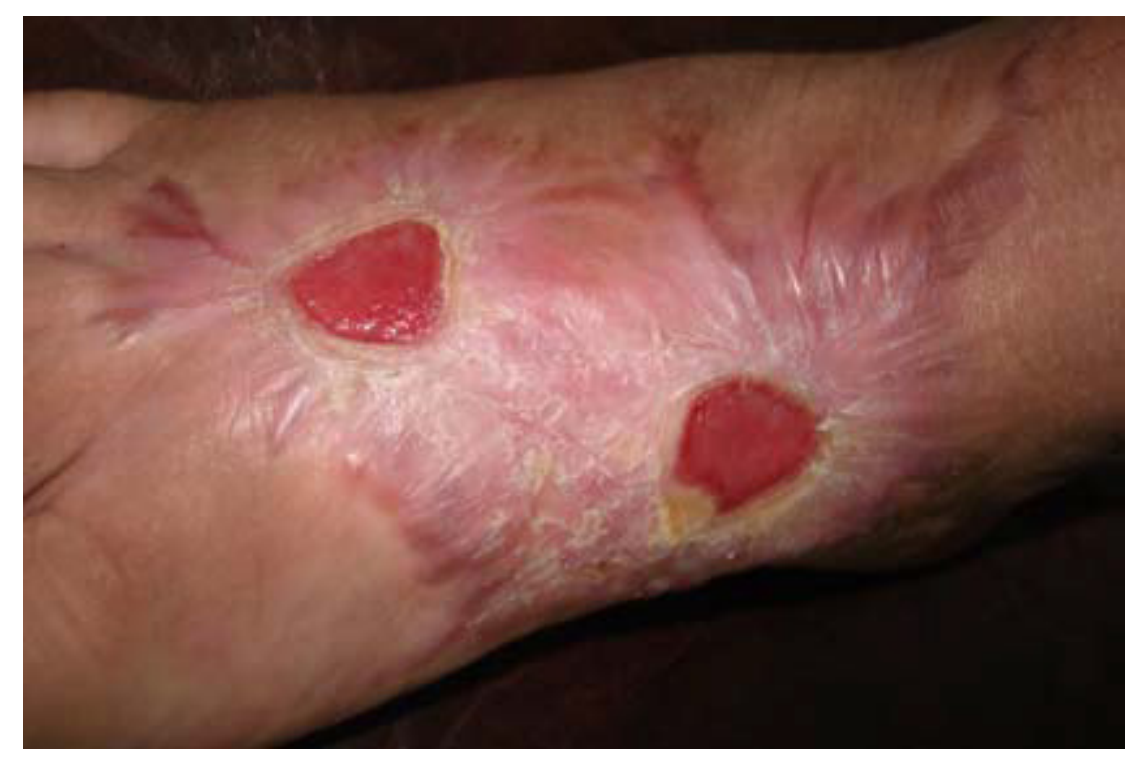

Fig. 5. The presentation of ulcer after 2 weeks treatment by AVG and potassium permanganate alternatively daily.

treat with minimum concentration and in the case of not complication then increasing the concentration daily.

In this case, after two weeks (week 8) the ulcer had no secretions by using potassium permanganate (Figure 4).

The healing of ulcer was begun by applying potassium permanganate shower, but because the healing process was stopped, Aloe vera gel was advised to be used. Then Aloe vera gel and potassium permanganate were employed alternately. (In the morning Aloe vera gel and in the afternoon the potassium permanganate) (Figure $5)$.

By applying potassium permanganate the ulcer became dried and no secretion, (week 10) so potassium permanganate discontinued and applying Aloe vera gel is advised solely for two week (Week 12) (Figure 6). 


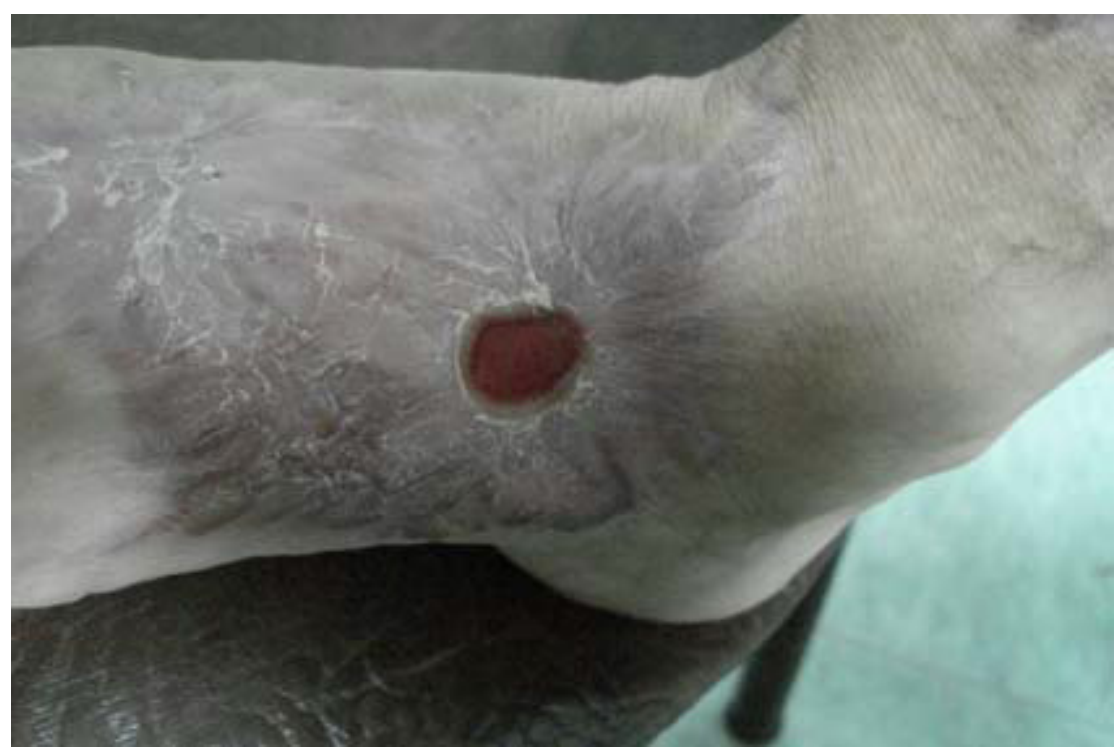

Fig. 6. The presentation of ulcer after 2 weeks treatment by AVG alone.

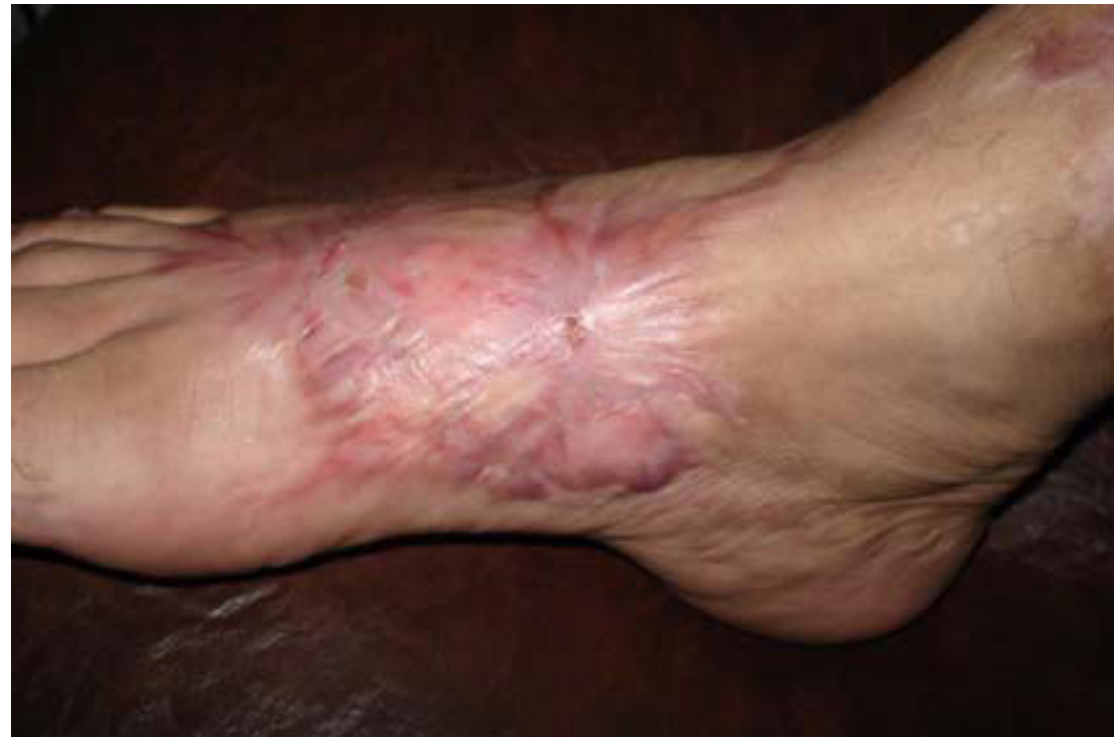

Fig. 7. The presentation of closed ulcer after 2 weeks more treatment by AVG alone.

The healing process was continued for another two weeks until achieving complete healing of ulcer (Week 14) (Figure 7).

\section{Discussion and Conclusion}

Aloe vera is a particular herb in tropical area which may strengthen the healing process by impression on some phases like inflammation, fibroplasia, collagen synthesis, ulcer maturation and limitation ${ }^{13}$. As it can be observed in Figure 2, after employing Aloe vera gel for two weeks ulcer starts to become limited. Previous studies indicated that Aloe vera gel is expedited for healing process ${ }^{9-11,14,15}$. Healing process is caused by direct stimulation of macrophages and fibroblasts activity ${ }^{16}$.

Aloe vera can prevent inflammation process with reducing the adhesion of leucocytes and preinflammation cytokines like TNF-alpha and II- $6^{15}$.

In this study, the Aloe vera gel dressing led to reduce the pain, secretion and redness of ulcer. (Figure 2). 
Angiogenesis process is one of the important processes in ulcer healing. beta-sitosterol is one of the final productions of analysis of the Aloe vera gel which has potential angiogenesis activity. beta-sitosterol may have potential ability as a medication in treatment of chronic ulcers ${ }^{17}$.

It probably looks like that angiogenesis of Aloe vera gel is the main reason of the ulcer healing in this case.

In Addition, uptodate, several active ingredients of Aloe vera gel have been identified. It has been shown that polysaccharides of Aloe vera, has indirect bactericidal activity by stimulating the phagocytic function of leukocytes ${ }^{18}$. It is reported that Aloe vera can stimulate gap junctional intercellular communication and dermal fibroblasts multiplication in diabetes patients to help ulcer healing ${ }^{19}$. It looks like that glucosamine is the limiting substance for hyaluronic acid production in ulcer. Aloe vera may have effectiveness on ulcer repairing and immune system function ${ }^{20}$.

Aloe vera gel has potential effect on healing chronic ulcers process, but in this case, raising the question whether ulcer healing process was stopped after employing Aloe vera gel dressing for six weeks.

Administration of $\mathrm{KMnO}_{4}$ promotes the healing process in our patient. Potassium permanganate, as an oxidation, has antiseptic effect. For example, the diluted solution of potassium permanganate is disinfectant of the ulcers and it is used for treatment in some mild cases of dermatitis ${ }^{13,21,22}$ superficial fungal infections of hand and foot ${ }^{23}$ and in some areas to treat the candidiasis infections ${ }^{24}$. One study shows that potassium permanganate is effective on skin infection caused by Fusarium which produce painful ulcer on the leg of a woman with natural immunity ${ }^{25}$. Another study showed the ulcer, in a lesion of squamous cell carcinoma involved with myiasis, treated by plugging into potassium permanganate solution ${ }^{26}$.

This report believes that prescription of $\mathrm{KMnO}_{4}$ caused to drying the ulcer and provides a suitable condition for Aloe vera gel effect.

The first analysing of this case is a super-infection on ulcer. For assessment of this issue, tissue culture was requested and negative answer of this case rejected any contamination. Regarding to employ Aloe vera gel which has potential antibacterial effect and prevent it to be infected, the finding was completely reasonable.

This conducted treatment gives rise several questions:

1. Is there resistance to Aloe vera gel in healing process of disease?

2. Has there been any unusual infection which was not recognised by usual culture and was treated by antiseptic effect of potassium permanganate and this infection has prevented healing process?

3. Is there any synergistic effect between Aloe vera gel and permanganate potassium solution in the healing process of ulcer?

These and many other questions need more studies to be answered.

\section{References}

1. Eckman KL. The prevalence of dermal ulcers among persons in the US who have died. Advances in Skin \& Wound Care. 1989; 2(2):36-9.

2. Dharmarajan $\mathrm{T}$, Ahmed $\mathrm{S}$. The growing problem of pressure ulcers. Evaluation and management for an aging population. Postgraduate medicine. 2003; 113(5):77.

3. Ratliff C, Rodeheaver G. Pressure ulcer assessment and management. Lippincott's primary care practice. 1999; 3(2):242.

4. Higgins $\mathrm{K}$, Ashry $\mathrm{H}$. Wound dressings and topical agents. Clinics in podiatric medicine and surgery. 1995; 12(1):31.

5. Goode PS, Thomas DR. Pressure ulcers. Local wound care. Clinics in geriatric medicine. 1997; 13(3):543.

6. Goudarzi Y, Khodadadyan C, Hertel P. Clinical experience with collagenous wound dressing in severe traumatic soft tissue injuries. AktuelleTraumatologie. 1992; 22(5):214.

7. Oancea A, Popa E, Zărnescu O, Angelescu N. The effects of cicatrizant wound compresses. Chirurgia (Bucharest, Romania: 1990). 2000; 95(3):245.

8. Hartman D, Coetzee J. Two US practitioners' experience of using essential oils for wound care. Journal of wound care. 2002; 11(8):317-20.

9. Avijgan M. Phytotherapy: an alternative treatment for nonhealing ulcers. Journal of wound care. 2004; 13(4):157-8.

10. Avijgan M. Aloe Vera Gel is more effective than conventional treatment in chronic ulcers. Book abstract of International Congress: Safety Evaluation of Complementary and Alternative Medicine. Employ Italy, 24-25 October 2003. p. 51. 
11. Avijgan M, Broujeni VB, Beigi AA, Borojeni HR, Hafizi M, Mostafavizadeh SK, Karimi I, Javadi AA. Healing effect of Aloe vera gel in non healed ulcers. Asian Pac J Trop Med. 2009; 2(1):1-6.

12. Lejeune C, Moutard-Codou M, Lavaud J. Methods of prescribing potassium permanganate baths. Prevention of caustic complications. Archives françaises de pédiatrie. 1984; 41(4):295.

13. Stalder J, Fleury M, Sourisse M, Allavoine T, Chalamet C, Brosset P, Litoux, P. Comparative effects of two topical antiseptics (chlorhexidinevs KMn04) on bacterial skin flora in atopic dermatitis. ActadermatovenereologicaSupplementum. 1992; 176:132.

14. Chithra P, Sajithlal G, Chandrakasan G. Influence of Aloe vera on the healing of dermal wounds in diabetic rats. Journal of ethnopharmacology. 1998; 59(3):195-201.

15. WHO Monograph of Aloe Vera, Geneva. 1998.

16. Duansak D, Somboonwong J, Patumraj S. Effects of Aloe vera on leukocyte adhesion and TNF-alpha and IL-6 levels in burn wounded rats. Clin Hemorheol Microcirc. 2003; 29(3-4):239-46.

17. Moon EJ, Lee YM, Lee OH, Lee MJ, Lee SK, Chung MH, Park YI, Sung CK, Choi JS, Kim KW. A novel angiogenic factor derived from Aloe vera gel: beta-sitosterol, a plant sterol. Angiogenesis. 1999; 3(2):117-23.

18. Ferro VA, Bradbury F, Cameron P, Shakir E, Rahman SR, Stimson WH. In vitro susceptibilities of Shigellaflexneri and
Streptococcus pyogenes to inner gel of Aloe barbadensis Miller. Antimicrobial agents and chemotherapy. 2003; 47(3):1137-9.

19. Abdullah KM, Abdullah A, Johnson ML, Bilski JJ, Petry K, Redmer DA, Reynolds LP, Grazul-Bilska AT. Effects of Aloe Vera on gap junctional intercellular communication and proliferation of human diabetic and no diabetic skin fibroblasts. J Altern Complement Med. 2003 Oct; 9(5):711-8.

20. MacKay D, Miller AL. Nutritional support for wound healing. Alternative Medicine Review. 2003; 8(4):359-77.

21. Birt AR. Drugs for eczema of children. Canadian Medical Association Journal. 1964; 90(11):693.

22. Burriel F, Lucena F, Arribas S, Hernández J. Química Analítica Cualitativa, 1985. p. 688.

23. Program for Appropriate Technology in Health PATH "Skin diseases". Health Technol Dir. 1988; 8 (3):1-10. Available from http://www.ncbi.nlm.nih.gov/pubmed/12282068

24. Hasteline F, Yaw Y. Woman Doctor: The Internship of a Modern Woman. Boston, MA: Houghton Mifflin Co; 1976.

25. Ruiz dCA, Herrera A, Suárez AI, Camacho FM. Skin infection with Fusarium in an immunocompetent patient. Actas dermo-sifiliográficas. 2006; 97(4):278.

26. Namazi M, Fallahzadeh MKM. Wound myiasis in a patient with squamous cell carcinoma. The Scientific World Journal. 2009; 9:1192-3. 